1. Ph.D., Assistant Professor, Department of Statistics, Bahauddin Zakariya University, Multan, Pakistan.

2. Lecturer,

Govt. College, Muzzafarghar, Pakistan.

3. Ph.D., Assistant Professor Department of Statistics, Bahauddin Zakariya University, Multan, Pakistan.

Correspondence Address:

Dr. Muhammad Aslam

Assistant Professor,

Department of Statistics,

Bahauddin Zakariya University,

Multan, Pakistan.

aslamasadi@bzu.edu.pk

Article received on:

07/11/2014

Accepted for publication:

20/12/2014

Received after proof reading:

$17 / 04 / 2015$

\section{TOBACCO SMOKING;}

ASSOCIATION AND RISK OF LEADING CANCERS AMONG MALES IN THE SOUTHERN PUNJAB, PAKISTAN

\author{
Dr. Muhammad Aslam ${ }^{1}$, Muhammad Asif ${ }^{2}$, Dr. Saima Altaf ${ }^{3}$
}

ABSTRACT... Objective: To assess the risk of different cancer sites among the male smokers of the Southern Punjab, Pakistan. Study Design: Case-control design. Period: March - July 2012. Setting: A data set of 596 males, belonging to the Southern Punjab was collected from the Outdoor Ward of Cancer, Oncology Ward of Nishtar Hospital and Multan Institute of Nuclear Medicine and Radiotherapy (MINAR) Hospital. Method: Through a self-administered questionnaire, smoking status and respondent's history and medical record of various types of cancers were noted. The Chi-square test was used to assess the association between tobacco smoking and cancer disease. For the risk analysis, odds ratios and attributable risk were computed. Results: Among the respondents, 49.0\% smoked tobacco. From the medical record, 438 respondents were confirmed cancerous. The average age to start tobacco was noted to be $23.41 \pm 4.85$ while the age was $45.29 \pm 12.24$ years for tobacco cessation. The percentage of lung cancer among smokers is 24.01 which is highest among all the stated cancer sites. The risk of a smoker getting all types of the stated cancers is at least three times. The risk of lung cancer attributed to smoking is 17.65 and $50.7 \%$ of all the stated cancers. Conclusions: Smokers in the Southern Punjab can greatly reduce their risk (more than $50 \%$ ) of cancer if they quit smoking.

Key words: $\quad$ Attributable risk, Lung cancer, Odds ratio, Tobacco smoking.

Article Citation: Aslam M, Asif M, Altaf S. Tobacco smoking; association and risk of leading cancers among males in the southern Punjab, Pakistan. Professional Med $\mathrm{J}$ 2015;22(4):460-465.

\section{INTRODUCTION}

Cancer disease is one the most fatal diseases, related to the public health around the world. In the science of epidemiology, the disease of cancer is also known as malignant tumor or malignancy. There are about 200 different known cancers that affect humans. ${ }^{1}$

It is very difficult to know about what certain causes account the risk of cancer. However, in addition to some recognized potential risk factors for cancer, such as lack of physical activity, certain wounds, radiations, fatness and environmental pollutants etc. ${ }^{2-5}$ Use of tobacco and different tobacco products are also the risk factors for cancer, worldwide. Many studies have been tried to find the risk of particular cancer type caused by tobacco smoking ${ }^{6-9}$. The main sites of cancer, related to tobacco smoking are lungs, stomach, kidney, urinary bladder and esophagus etc ${ }^{7-9}$.
Cancer is one of the major health problems in Pakistan. Cancer disease has become more important disease as a public health concern in Pakistan. Punjab is the most populous province of Pakistan and in its southern zone; three divisions are situated named as Multan division, D.G. Khan Division and Bahawalpur division which cover area of the south Punjab. The literature survey indicated that work on the prevalence of cancer disease due to tobacco smoking in the region of South Punjab, has not been carried out. This motivated us to find the relationship between the effects of tobacco smoking and various leading cancers in the wide area of the Southern Punjab. In the present study, we focus on the risk of cancer disease among males in relation to tobacco smoking.

\section{METHODOLOGY}

\section{Settings}

For the present work, we conducted a case- 
control study to evaluate the association between tobacco smoking and risk of different types of cancer. A sample of 596 individuals has been collected during March, 2012 to July, 2012 from the Outdoor Ward of Cancer, Oncology Ward of Nishtar Hospital, Multan and MINAR Hospital.

In the present case-control study, for the identification of the patients whether they belong to case series, their medical records were checked if the patients were affected with some cancer they were considered as cases.

\section{Inclusion and Exclusion Criteria}

Our data consists of those male respondents who come for medical check-up of different cancer sites from Multan Division, D.G Khan Division and Bahawalpur Division. The patients other than cancer disease are not included.

\section{Variables and Data Management}

For the present study, the data were collected through an interview of self-administered questionnaire. The questionnaire had two sections. The first section consisted of respondent's history about tobacco smoking. Tobacco smoking was addressed through question on smoking status (i.e. never smoker, current smoker and former smoker). Never smoker was defined as a person who never smoked. The current smokers were defined as those respondents who smoked throughout their follow-up periods and former smokers were those who had to stop tobacco smoking for at least one year before our study. The questions were asked about the age of the respondent, type of tobacco product (cigarettes/ hookah/cigar/pipe) smoked, starting age tobacco smoking, consumption of cigarettes/ hookah/cigar/pipe smoking per day, duration for cigarettes/hookah/cigar/pipe smoked and age at quitting (cessation) of tobacco smoking for the former smokers.

The second section of the questionnaire consisted of respondent's history and medical record of various types of cancer. The age at which the respondent affected from the cancer, was also asked in this section.

\section{STATISTICAL METHODS}

We apply the Chi-square test to test whether there is significant relationship between cancer disease status and tobacco smoking and also check the association between cancer disease status and respondent's age-group.

The case-control studies can not calculate incidences or prevalence. They can, however, calculate odds ratio (OR). In the present research work, the risk is estimated using the ORs and their respective 95\% confidence intervals(Cls) for tobacco related cancer sites according to the type of tobacco smoker (for former and current smokers vs. never smokers) and for type of tobacco product smoked (for cigarettes and hookah smokers vs. never smokers).

The OR is the ratio of the odds of an event occurring in one group to the odds of it occurring in another group. The OR can be defined as

$$
O R=\frac{a / c}{b / d}=\frac{a d}{b c}
$$

where

$a=$ Number of exposed cases,

$b=$ Number of exposed non-cases (controls),

$c=$ Number of unexposed cases,

$\mathrm{d}=$ Number of unexposed non-cases (controls).

For the statistical inference about the OR, the large sample theory for the sampling distribution of the natural $\log$ of $\mathrm{OR}^{10}$, is used. Let $\psi$ be the $\log (\mathrm{OR})$ when the OR is based on the population data then using $\mathrm{Eq}(1)$, the estimated value of $\psi$ can be obtained as

$\hat{\psi}=\log \left(\frac{a d}{b c}\right)=\log (a)+\log (d)-\log (b)-\log (c)$.

$\hat{\psi}$ is distributed as normal distribution with mean,

$\psi$ and variance, $\sigma_{\hat{\psi}}^{2} .{ }^{10}$ While the S.E for the log

(OR) will be $S E(\hat{\psi})=\sqrt{\frac{1}{a}+\frac{1}{b}+\frac{1}{c}+\frac{1}{d}}$.

Now $95 \%$ confidence interval for the population

OR can be estimated as $\left(e^{\hat{\psi}-1.965 E(\hat{\psi})}, e^{\hat{\psi}+1.96 \text { SE }(\hat{\psi})}\right) .{ }^{11}$ 
In addition to the OR, the attributable risk (AR) is also measured. The AR (denoted by $\theta$ ) is estimated by

$$
\hat{\theta}=\frac{1}{a+c}\left\{(a+c)-\frac{n c}{c+d}\right\}=\frac{r-r_{\bar{E}}}{r} .
$$

Here $r$ is the overall risk of disease and $r_{-}$is the risk in the unexposed group for the sample ${ }^{E}$ data. ${ }^{12}$

Furthermore, $r=(a+c) / n$ and $r_{\bar{E}}=c /(c+d)$.

This will measure the proportion of cases of disease that are attributable to the risk factor.

We use the statistical software SPSS 16.0 and Minitab 15.0 to perform complete statistical analyses.

Ethic committee of Bahauddin Zakariya University Multan (Pakistan) approved all the experimental techniques.

\section{RESULTS}

In the data set of 596 individuals, the mean age of the respondents is 43.99 years (95\% C-I: 42.71, 45.27). Among the respondents, 292 $(49.0 \%)$ respondents smoke tobacco. Among the smokers, majority of the respondents $(87.5 \%)$ smoke cigarettes while $12.5 \%$ of the smokers use some other smoking products like hookah etc.
It is further reported that the average age to start tobacco smoking is $23.41 \pm 4.85$. To investigate whether the cancer patients are incident cases, their personal history and medical records are checked. Consequently, 438 (73.5\%) respondents are confirmed cancerous to define case series and $158(26.5 \%)$ respondents are not confirmed cancerous after a medical check-up.

It is found that majority of the respondents (54.0\%) belongs to Multan division. On the other hand, $30.5 \%$ and $15.5 \%$ respondents belong to D.G. Khan and Bahawalpur divisions, respectively.

It is reported that the mean age for smoking cessation (quit) by the smokers in the Southern Punjab is $45.29 \pm 12.24$. On the basis of quartiles, it is reported that $25 \%$ smokers quit smoking before the age of 35 while about $50 \%$ quit around the age of 45 . Only $25 \%$ of the smokers continue to smoke after age of 55 in the Southern Punjab.

Among the cigarette-smokers, majority of the smokers $(57.48 \%)$ smoke 5 to 10 cigarettes per day and the percentages of smoking of less than 5 cigarettes, 11 to 20 cigarettes and more than 20 cigarettes per day are 8.16, 25.85 and 8.50, respectively.

Table-I expresses the association between case/ control and different factors like, age group of

\begin{tabular}{|c|c|c|c|c|c|}
\hline Classification & Case & Control & Chi-Square & d.f & P-value \\
\hline \multicolumn{6}{|c|}{ Age group (years) } \\
\hline Less than 14 & 12 & 00 & 12.81 & 04 & 0.012 \\
\hline 14 to 30 & 75 & 41 & & & \\
\hline 31 to 40 & 94 & 41 & & & \\
\hline 41 to 60 & 196 & 61 & & & \\
\hline above 60 & 61 & 15 & & & \\
\hline \multicolumn{6}{|c|}{ Tobacco smoking status } \\
\hline Yes & 234 & 58 & 12.98 & 1 & 0.000 \\
\hline No & 204 & 100 & & & \\
\hline \multicolumn{6}{|c|}{ Type of tobacco product smoked } \\
\hline Cigarette & 211 & 44 & 8.60 & 1 & 0.003 \\
\hline Hookah etc. & 23 & 14 & & & \\
\hline
\end{tabular}

Table-I. Association between case/control status and different factors 
respondents, status of tobacco smoking, type of smoker and type of tobacco smoked. The Chisquare test reveals an association of the cancer disease with all the stated factors.

Among 438 cases, 159 non-smokers have such cancers which are not reported, in our study, among the smokers. These are cases of kidney, brain, blood and bone cancer etc. Thus, further analysis is based on 279 cases out of which 234 are smokers while 45 are non-smokers.

Fig. 1 shows that the percentage of lung cancer is highest among the smokers and that is almost four times as among the non-smokers. Next frequent types of cancers among smokers are stomach, esophagus and throat cancers, respectively.

The figures in Table Il show that the high prevalence

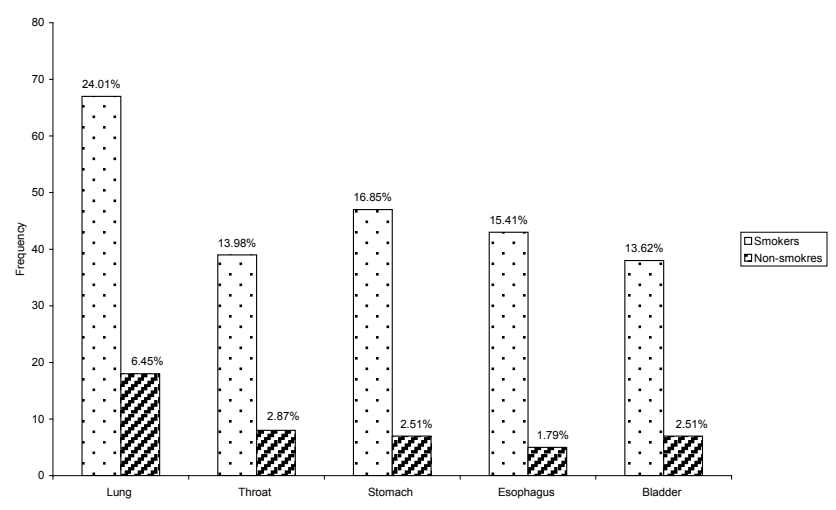

Fig-1. Distribution of different cancer sites among smokers and non-smokers

of cancer (of all the stated types) is alarming among the people, aged above 40. Among the cases of lung cancer, only $28 \%$ patients have ages 40 or below. Similarly, among the cases of esophageal and throat cancers, more than half of the patients belong to age group 41-60.

\begin{tabular}{|c|c|c|c|c|c|c|}
\hline Category & Lungs & Throat & Stomach & Esophagus & Ur. Bladder & Control \\
\hline No. of Subjects & $85(30.46)$ & $47(16.84)$ & $54(19.35)$ & $48(17.20)$ & $45(16.12)$ & 158 \\
\hline \multicolumn{7}{|c|}{ Age Groups (years) } \\
\hline $40-31$ & $17(20.00)$ & $08(17.20)$ & $12(22.20)$ & $14(29.20)$ & $09(20.00)$ & $41(25.94)$ \\
\hline $41-60$ & $51(60.00)$ & $26(55.30)$ & $22(40.70)$ & $25(52.10)$ & $30(66.70)$ & $61(38.60)$ \\
\hline \multicolumn{7}{|c|}{ Area of Residential Division } \\
\hline Multan Division & $41(48.20)$ & $23(48.90)$ & $27(50.00)$ & $24(50.00)$ & $23(51.10)$ & $85(53.80)$ \\
\hline D G Khan Division & $27(31.80)$ & $18(38.30)$ & $18(33.30)$ & $18(37.50)$ & $13(28.90)$ & $46(29.10)$ \\
\hline Bahawalpur Division & $17(20.00)$ & $06(12.80)$ & $09(16.70)$ & $06(12.50)$ & $09(20.00)$ & $27(17.10)$ \\
\hline
\end{tabular}

Table III shows the estimated ORs with their 95\% C-Is and estimated AR for different types of cancers in smokers relative to non-smokers. The computed ORs reveal that the risk of a smoker getting all types of the stated cancers is at least three times the risk of a non-smoker getting these cancers. For instance, the risk of a smoker getting lung cancer is about three times the risk of a nonsmoker getting lung cancer.

\begin{tabular}{|c|c|c|c|c|c|}
\hline Cancer site & $\mathbf{O R}^{\boldsymbol{*}}$ & $\mathbf{9 5 \%} \mathbf{C}$-I & $\mathbf{S E}$ & $\mathbf{p}$-value & AR $^{*}$ \\
\hline Lungs & 3.05 & $1.09-8.47$ & 0.5220 & 0.0329 & 0.1765 \\
\hline Throat & 3.75 & $1.22-11.51$ & 0.5723 & 0.0290 & 0.3381 \\
\hline Stomach & 3.84 & $1.18-12.45$ & 0.6005 & 0.0251 & 0.3432 \\
\hline Ur. Bladder & 3.80 & $1.08-13.37$ & 0.6419 & 0.0375 & 0.3111 \\
\hline Esophagus & 5.38 & $1.26-22.94$ & 0.7404 & 0.0231 & 0.3646 \\
\hline
\end{tabular}

Table-III. Odds Ratios and $95 \%$ confidence intervals of tobacco smoking associated with the risk of leading cancer ${ }^{\star}$ Reference category: Never smokers 


\section{DISCUSSION}

The stated study shows that the smokers have significantly greater risk for all cancers than their non-smoking counterparts. An available study ${ }^{13}$ shows that a number of Pakistani smokers try to quit smoking when they are aged under 45 . A similar figure about the smoking cessation is found about the Southern Punjab where the average age at cessation is $45.29 \pm 12.24$ and about $50 \%$ quit smoking near age of 50 . Similar to many studies ${ }^{13-15}$, it is found that lung cancer is the site with the highest frequency among the smokers. The other three leading sites of cancer in the smokers of the Southern Punjab are stomach, esophagus and throat, respectively.

It is reported that the smokers at age 40 or above are more likely to become target of cancer suggesting the smokers to quit smoking at least before the age of 40 . It is reported that the smokers of different age groups are at risk of different types of cancers.

The risks of different cancers attributed to cigarette smoking have not been properly addressed about the Pakistani smokers. Many international studies $^{16,}$ claim more than $50 \%$ risk of lung cancer attributed to smoking. According to our study, although the frequency of the lung cancer is high among the smokers as stated earlier but the AR is $17.65 \%$. The risk of esophageal cancer, attributed to smoking, is double than that of the lung cancer in region of the Southern Punjab.

Finally, a principal observation in this study is that $50.7 \%$ of total stated cancer risk can be attributed to cigarette smoking.

\section{CONCLUSIONS}

The data of 596 individuals from the Southern Punjab, Pakistan reveal that about half of the males smoke tobacco in any form, especially cigarettes. In the said region, males tend to start smoking in early 20s and if they decide to cease smoking then it happens after $40 \mathrm{~s}$. It is found that the percentage of lung cancer is highest among the smokers. Overall, top three leading cancer sites are lungs, stomach and esophagus, respectively but the cancer sites are different among the smokers of different age groups. Furthermore, the smokers above age of 40 are more likely to be cancerous. The study observed that $17.65 \%, 36.46 \%$ and $33.81 \%$ of lung, esophageal and throat cancer incidence, respectively among smokers could have been avoided if the smokers had never smoked tobacco. The data also suggest that up to $50.7 \%$ of the incidence of all the stated cancers among the smokers could be avoided if they had never smoked.

Copyright@ 20 Dec, 2014.

\section{REFERENCES}

1. Andrew K, Dollinger M, Rosenbaum EH. Every One's Guide to Cancer Therapy. Andrews McMeel Publishing, LLC, Cansas City 2008; 241-264.

2. Anand $P$, Kunnumakkara $A B$, Sundaram $C$, Harikumar KB, Tharakan ST, Lai OS, Sung B, Aggarwal BB. Cancer is a preventable disease that requires major lifestyle changes. Pharm Res 2008; 25: 2097-2116.

3. Kampa M, Castanas E. Human health effects of air pollution. Environmental Pollution 2008; 151: 362-367.

4. Smith EM, Rubenstein LM, Haugen TH, Hamsikova E, Turek LP. Tobacco and alcohol use increases the risk of both HPV-associated and HPV-independent head and neck cancers. Cancer Causes Control 2010; 21:1369-1378.

5. de Martel C, Ferlay J, Franceschi S, Vignat J, Bray F, Forman D, Plummer M. Global burden of cancers attributable to infections in 2008: a review and synthetic analysis. The Lancet Oncology 2012; 13: 607-615.

6. World Health Organization. Disease and injury country estimates: Burden of disease. WHO 2009(http://www.who.int/healthinfo/global_burden _disease/estimates_country/en/).

7. Boffetta P. Tobacco smoking and risk of bladder cancer. Scandinavian Journal of Urology and Nephrology 2008; 42: 45-54.

8. Cui $Y$, Miller AB, Rohan TE. Cigarettes smoking and breast cancer risk: update of a prospective cohort study. Breast Cancer Research and Treatment 2006; 100: 293-299.

9. Ljungberg B, Campbell SC, Choi HY, Jacqmin D, Lee JE, Weikert S, Kiemeney LA. The epidemiology of renal cell carcinoma. The Journal of Urology 2011; 60: 615621. 
10. Morris JA, Gardner MJ. Calculating confidence intervals for relative risks (odds ratios) and standardized ratios and rates. British Medical Journal 1988; 296: 1313-1316.

11. Sistrom CL, Garvan CW. Proportions, odds, and risk. Radiology 2004; 230: 12-19.

12. Woodward M. Epidemiology: Study Design and Data Analysis. Chapman \& Hall/CRC 2004.

13. White M, Bush J, Kai j, Bhopal R, Rankin J. Quitting smoking and experience of smoking cessation interventions among UK Bangladeshi and Pakistani adults: The views of community members and health professionals. J Epidemiol Community Health 2006; 60:405-411.
14. Shihadeh A, Azar S, Antonios C, Haddad A. Towards a topographical model of narghile water-pipe café smoking: a pilot study in a high socioeconomic status neighborhood of Beirut, Lebanon. Pharmacol Biochem Behav 2004; 79: 75-82.

15. Ahmed R, Rizwan-ur-Rashid, McDonald PW, Ahmed W. Prevalence of cigarette smoking among young adults in Pakistan. J Pak Med Assoc 2008; 58: 597-601.

16. Ando M, Wakai K, Seki N, Tamakoshi A, Suzuki K, Ito Y, Nishino Y, Kondo Y, Watanab Y, Ozasa K, Ohno Y. Attributable and absolute risk of lung cancer death by smoking status: findings from the Japan collaborative cohort study. Int J Cancer 2003; 105: 249 -254 .

\section{"Education is learning what you didn't even know you didn't know."}

\section{Daniel J. Boorstin}

\begin{tabular}{|c||c|c|c|}
\hline \multicolumn{3}{|c|}{ AUTHORSHIP AND CONTRIBUTION DECLARATION } \\
\hline Sr. \# & \multicolumn{1}{|c|}{ Author-s Full Name } & \multicolumn{1}{|c|}{ Contribution to the paper } & Author=s Signature \\
\hline 1 & Dr. Muhammad Aslam & $\begin{array}{l}\text { Conceived the idea, laid out the } \\
\text { design and statistical framework. } \\
\text { Primary draft of the manuscript. }\end{array}$ \\
\hline 2 & Muhammad Asif & $\begin{array}{l}\text { Data collection and statistical } \\
\text { analysis } \\
\text { Interpretation of the result, } \\
\text { reviewing and editing of the draft. }\end{array}$ \\
\hline 3 & Dr. Saima Altaf &
\end{tabular}

